\title{
Narrativa e educação: algumas reflexões a partir de Benjamin, Kundera e Rorty
}

\author{
Narrative and education: some reflections \\ from Benjamin, Kundera and Rorty
}

\begin{abstract}
Heraldo Aparecido Silva
Professor adjunto do Departamento de Fundamentos da Educação na Universidade Federal do Piauí (UFPI), Teresina, PI - Brasil, e-mail: heraldokf@yahoo.com.br
\end{abstract}

\section{Resumo}

Este artigo analisa alguns aspectos da noção de narrativa à luz das ideias do filósofo alemão Walter Benjamin (1892-1940), do literato tcheco Milan Kundera (1929-) e do filósofo norte-americano Richard Rorty (1931-2007). A fundamentação teórica de nosso estudo estará centrada, principalmente, no conhecimento advindo a partir de autores como: Benjamin (1975, 1986), Kundera (1988, 1994), Rorty $(1990,1994,1995,1997,1998,2000)$ e Orwell (1996). Assim, a interpretação dos textos dos autores estudados e a posterior confrontação de suas ideias permitirão relacioná-las conceitualmente com a temática proposta. Finalmente, propomos mostrar que, em alguns momentos e a despeito das diferenças teóricas entre Benjamin, Kundera e Rorty, suas vozes ecoam importantes mensagens em comum para a educação.

Palavras-chave: Narrativa. Benjamin. Kundera. Rorty. Educação. 


\section{Abstract}

This article analyze some aspects of narrative notion in light of the ideas of German philosopher Walter Benjamin (1892-1940), of literary Czech Milan Kundera (1929-) and the American philosopher Richard Rorty (1931-2007). The theoretical basis of our study is focused primarily on the knowledge gained from authors such as: Benjamin $(1975,1986)$, Kundera $(1988$, 1994), Rorty (1990, 1994, 1995, 1997, 1998) and Orwell (1996). Thus, the interpretation of texts from authors studied and further confrontation of their ideas will relate them conceptually with the proposed theme. Finally, we propose to show that in some moments and despite theoretical differences between Benjamin, Kundera and Rorty, your voices echo important messages in common to education.

Keywords: Narrative. Benjamin. Kundera. Rorty. Education.

\section{Introdução}

O propósito deste artigo é tecer algumas breves considerações acerca da relação entre filosofia, literatura e educação a partir da noção de narrativa segundo as ideias do filósofo alemão Walter Benjamin (18921940) e do filósofo norte-americano Richard Rorty (1931-2007). A despeito das divergências teóricas entre a Escola de Frankfurt e o Pragmatismo, respectivamente as orientações filosóficas de Benjamin e Rorty, não pretendemos acirrar mais esse debate, contrapondo em minúcias suas teses, visto que tal medida excederia o escopo deste trabalho.

Desse modo, nosso percurso principia com uma explanação acerca das reflexões de Benjamin e Rorty em torno da noção de narrativa. Entre ambos, uma breve, porém necessária incursão pela noção de hipótese ontológica romanesca extraída dos escritos do literato Milan Kundera (1929-). No decorrer do texto, faremos alguns apontamentos a fim de evidenciar a complementaridades das três extemporâneas contribuições. No caso de Benjamin, evidenciaremos sua conceituação de narrativa atrelada ao seu papel moralizante e de compartilhamento de experiências, 
funções atribuídas tanto aos narradores quanto aos sábios e educadores. Em Kundera, delinearemos um contraponto entre o saber romanesco e o filosófico. Sobre Rorty destacaremos sua defesa da narrativa em detrimento da teoria como um recurso mais eficaz para a efetivação da solidariedade humana.

Finalmente, a partir das ideias dos três autores estudados interpretamos determinados tópicos da obra 1984 de George Orwell (19031950) de modo a destacar algumas possibilidades de tais reflexões para estudos e pesquisas no campo educacional.

\section{Benjamin e a arte da narrativa}

O filósofo alemão Walter Benjamin principia suas considerações sobre a narrativa com uma constatação que é quase um vaticínio: o fim da narrativa é iminente. Para ele, é cada vez mais raro encontrar alguém capaz de narrar algum evento. É como se, subitamente, as pessoas tivessem perdido a capacidade de trocar por meio de palavras suas experiências vividas.

A paulatina supressão da narrativa seria uma consequência da coibição cada vez mais intensa das experiências individuais numa época caracterizada por céleres transformações históricas, econômicas e políticas. Um exemplo de como tais vicissitudes mundiais modificaram de maneira esmagadora a vida - e, portanto, as experiências - de boa parte das pessoas diz respeito aos traumas advindos de uma guerra que, ao contrário das anteriores, restringiu as possibilidades radiantes de heroísmos particulares pelo anonimato funesto das trincheiras.

Benjamin (1975) acredita que, na tradição dos relatos orais, há dois grupos estreitamente vinculados, respectivamente denominados de vagantes e sedentários. No primeiro caso, os relatos dizem respeito ao mundo exterior e os narradores são pessoas que viajaram pelo mundo e trazem histórias estrangeiras para contar; no segundo caso, os relatos tratam dos acontecimentos locais e os narradores são pessoas que permaneceram em suas comunidades originais e preservam as histórias nativas. Em ambos, a transmissão da experiência, qualquer que seja a sua estirpe, 
visa ao "interesse prático" e é feita sob a forma de conselhos, pois o narrador tem sempre uma tarefa definida, seja a transmissão de uma moral, de um ensinamento prático, de um provérbio ou de uma "regra fundamental da existência" (1975, p. 65). E continua:

pois 'dar conselho' significa muito menos responder a uma pergunta do que fazer uma proposta sobre a continuidade de uma história que neste instante está a se desenrolar. Para formular o conselho é necessário antes de mais nada, saber narrar a estória. (Além disso, um indivíduo é receptivo a um conselho apenas na medida em que expõe a sua situação.) Um conselho fiado no tecido da existência vivida, é sabedoria. A arte de narrar aproxima-se do seu fim por extinguir-se o lado épico da verdade, a sabedoria (BENJAMIN, 1975, p. 65).

Nessa perspectiva, Benjamin (1975) também sustenta que a decadência da narrativa é marcada pela ascensão do romance.

A experiência propicia ao narrador a matéria narrada, quer a experiência seja própria ou relatada. E, por sua vez, transforma-se na experiência daqueles que ouvem a estória. O romancista escolheu um campo segregado. O local de origem do romance é o indivíduo na sua solidão, que já não sabe discutir, de forma exemplar, os seus assuntos mais prementes, que precisaria de ajuda, sem tê-la, e que ele próprio não sabe transmitir conselhos de qualquer natureza (BENJAMIN, 1975, p. 66).

Podemos exemplificar por meio do clássico romance Dom Quixote que contempla a existência humana no que ela tem de melhor em atributos virtuosos e impulsos volitivos, porém, não em sabedoria. Seu protagonista, o Cavaleiro da Triste Figura, personifica valores de nobreza inquestionável, mas é destituído, entretanto, de qualquer traço de sabedoria. As posteriores tentativas de dotar o romance de sabedoria resultaram na transformação da sua forma, do gênero em si. Como veremos posteriormente, esta concepção contraria a posição de Kundera segundo a qual o romance produz um tipo específico de sabedoria, a sabedoria da incerteza. E, ainda, especificamente, a oposição benjaminiana 
entre narrativa e romance é contrária à ampliação desmesurada de Rorty (1994) que, ao se referir a narrativas, realiza um amálgama de tais gêneros citados com outros, inclusive, com o texto jornalístico.

Benjamin (1975) ainda adverte que a informação (jornalística), uma nova forma de comunicação humana, além de levar o romance a uma crise configura uma ameaça ainda maior para a narrativa. Isto porque:

[a] informação capaz de oferecer alguma ligação com a vida prática é recebida com mais agrado do que o relato de situações e descrições longínquos ou de tempos afastados. Este dispunha de uma autoridade que o valorizava, mesmo que não pudesse ser controlado. A informação, contudo, baseia-se na sua verificabilidade. Por isso é evidente que aparece em forma 'facilmente inteligível'. Muitas vezes não é mais exata do que o era o relato de séculos anteriores. Mas enquanto este gostava de recorrer ao milagre, não dispensa a informação o caráter de verossimilhança, e, por isso, não pode ser conciliada com o espírito da narrativa. Se a arte de narrar reveste-se hoje de raridade, parte decisiva da culpa por essa situação cabe exatamente à difusão de informações (BENJAMIN, 1975, p. 67).

Nesse sentido, vale ressaltar o fato que a interpretação da narrativa, desde os tempos de Heródoto, fica a critério do ouvinte, uma vez que o narrador, voluntariamente, se destitui da primazia da explicação: ele nada explica ou informa, apenas relata; e o ouvinte interpreta e repassa a estória. Assim, entre a narrativa e a informação, é possível ressaltar a seguinte diferença crucial: enquanto a primeira reveste-se da novidade e se esvai no exato instante de sua revelação, a última pode perdurar e desenvolver-se indefinidamente.

Para Benjamin (1975, p. 69), narrativa e narrador se confundem por intermédio da forte inclinação que os narradores possuem de começarem a história a ser narrada, com uma "apresentação das circunstâncias nas quais foram informados daquilo que em seguida passam a contar; isto quando não apresentam todo o relato como produto de experiências próprias". Paradoxalmente, na acepção benjaminiana, há a ressalva que espectadores 
atribuem uma autoridade maior não aos narradores que estão no auge de sua vida, mas sim àqueles que estão próximos de findar sua existência.

Entretanto, é digno de observação que não apenas o conhecimento ou a sabedoria dos indivíduos, mas principalmente a sua vida vivida - a matéria formadora das estórias - assume formas transmissíveis, especialmente notáveis no moribundo. Assim como no fim da vida uma seqüência de imagens se põe em movimento no íntimo da pessoa composta das suas opiniões acerca dos outros e de si mesmo -, cristaliza-se repentinamente em sua mímica e seus olhos aquilo que lhe é inesquecível, atribuindo a tudo que é do seu interesse aquela autoridade de que todos, mesmo os mais pobres diabos, dispõem na hora da morte, perante os vivos. Na origem da narrativa existe esta autoridade (BENJAMIN, 1975, p. 70-71).

Desse modo, Benjamin sugere que a explicação para tal autoridade talvez resida na ideia mórbida, porém verdadeira, de que o moribundo ao proferir as suas derradeiras palavras, outorga à morte o poder de sancionar qualquer relato do narrador.

Ao tratar das características dissonantes entre o gênero narrativo e o romanesco, Benjamin destaca as noções de recordação e memória que, segundo ele, se filiam respectivamente à narrativa e ao romance. O filósofo alemão acredita que a diferença entre a narrativa e o romance pode ser também verificada, inclusive, na condição de seus respectivos espectadores. Para ele, enquanto o ouvinte de uma narrativa (inclusive o que a lê) estará sempre acompanhado pelo narrador; em contrapartida, o leitor de um romance, por sua vez, será sempre o mais solitário de todos os leitores.

Benjamin (1975, p. 75-76) sustenta ainda que os principais representantes da categoria dos narradores se encontram primordialmente entre as "camadas artesanais", pois acredita que os "grandes narradores" têm "suas raízes no povo" e se movem com facilidade, para cima e para baixo, "nos degraus de suas experiências". Finalmente, a derradeira constatação de Benjamin (1975, p. 81) enfatiza que o "narrador alinha-se entre os educadores e os sábios", pois assim como eles também é capaz de 
entremear-se em toda uma existência: composta não somente pelas suas experiências, mas também pelas de outras pessoas.

\section{Kundera e a hipótese ontológica}

Milan Kundera (1988) alega que a distinção tradicional entre literatura e filosofia torna-se obsoleta à medida que contestamos a primazia do saber científico-filosófico sobre o saber romanesco. Ele nos adverte sobre a possibilidade do romance ter assumido um propósito originalmente filosófico, a paixão de conhecer, tema inaugurado pela abrangente filosofia grega antiga e abandonado pela restringente filosofia europeia moderna. Kundera (1988, p. 10) acredita que toda análise sobre a modernidade que não leve em consideração o romance é lacunar e equivocada porque "o fundador dos Tempos Modernos não é somente Descartes mas também Cervantes”.

Para Kundera (1988, p. 12), ao contrário de Descartes que compreendeu "o ego pensante como fundamento de tudo", Cervantes compreendeu "o mundo como ambigüidade" e, por isso, teve que enfrentar não apenas uma verdade absoluta, mas uma miríade de verdades relativas e contraditórias, além de possuir como "única certeza a sabedoria da incerteza". Desta forma, podemos compreender que o campo romanesco é habitado por exceções e não por regras.

O homem deseja um mundo onde o bem e o mal sejam nitidamente discerníveis, pois existe nele a vontade inata e indomável de julgar antes de compreender. Sobre essa vontade estão fundadas as religiões e as ideologias. Elas não podem se conciliar com o romance a não ser que traduzam sua linguagem de relatividade e ambigüidade no próprio discurso apodíctico e dogmático. Elas exigem que alguém tenha razão [...] (KUNDERA, 1994, p. 12-13).

Kundera (1988, p. 72) discorre sobre a existência de uma diferença estrutural fundamental entre as reflexões filosóficas e as reflexões e digressões romanescas: aquelas são elaboradas no "domínio das 
afirmações", estas são compostas no "território do jogo e das hipóteses". E, ao contrário do que ocorre no discurso filosófico, no discurso romanesco o autor é destituído de sua primazia assertiva pois, no romance há um nexo inquebrantável entre a reflexão e o ego experimental: toda meditação, afirmação e negação é feita através de personagens, ou seja, egos experimentais. Outra diferença significativa diz respeito ao tratamento conferido aos temas abordados: enquanto na filosofia o tema é secundário; no romance ele é subjugante. O literato tcheco ainda afirma que um tema equivale a uma interrogação existencial, isto é, uma hipótese ontológica. A propósito do aspecto investigativo do romance, ele explica que toda obra romanesca, sem exceção, é uma incessante busca por respostas para o enigma do eu; e as personagens, que são seres imaginários, caracterizam hipóteses, tentativas de solução à interrogação existencial primeva.

A erudição de Rabelais, por maior que seja, tem portanto um outro sentido que a de Descartes. A sabedoria do romance é diferente daquela da filosofia. O romance nasceu não do espírito teórico mas do espírito do humor. [...] A arte inspirada pelo riso de Deus é, por sua essência, não tributária mas contraditória das certezas ideológicas. A exemplo de Penélope, ela desfaz durante a noite a tapeçaria que os teólogos, os filósofos, os sábios urdiram na véspera (KUNDERA, 1988, p. 141).

Assim, na concepção kunderiana, há a sugestão de um grande diálogo travado, de forma indireta, entre a vertente filosófica e a vertente romanesca do século XVIII. A ressalva é que tais interlocutores partiram de premissas opostas: a filosofia, aliada a ciência, concebia o mundo como causalidade; o romance, juntamente com a poesia, o entendia como possibilidade. Por conseguinte, se a filosofia busca um fundamento que justifique cada ação humana; o romance renuncia a esse propósito. 


\section{Rorty e as narrativas redescritivas}

Assim como Kundera, Rorty também pensa que a filosofia, a partir da modernidade, delimitou demasiadamente a sua temática quando centrou seu interesse na discussão acerca da verdade. Desde então, a filosofia teria se distraído - conforme o termo usado por Kundera - amplamente em relação à busca pela liberdade e, portanto, como consequência dessa negligência ela deve ser considerada como de pouca utilidade para a investigação sobre como ampliar liberdades. Em contrapartida, uma alternativa útil seria configurada por descrições revigorantes que, na acepção rortyana, é o que de fato funciona para criar liberdades ou expandir liberdades já existentes a fim de abarcar pessoas ou comunidades que anteriormente não eram lembradas ou privilegiadas.

Nesse momento, Rorty reconhece a existência de um equilíbrio argumentativo tanto na teoria quanto na narrativa, ou seja, aqueles que lutam para ampliar as liberdades individuais têm à sua disposição os mesmos recursos que os seus adversários, que tencionam tolher as mesmas. A diferença, segundo ele, é que nas teorias temos a pressuposição de que a cultura está estruturada plenamente por noções de validade transculturais; ao passo que, nas narrativas parte-se do princípio de que a cultura não está plenamente estruturada desta forma. A escolha de Rorty, implicitamente, baseia-se na esperança que nutre pela capacidade imaginativa dos seres humanos: como no segundo caso as possibilidades descritivas e os elementos a serem evocados são maiores - uma vez que elas não são limitadas previamente por nada -, ele espera que afortunadamente, as pessoas vislumbrem ou desejem utopias e não distopias. Através desta perspectiva, Rorty (1990, p. 637) redefine a própria tarefa do filósofo como "uma atividade de seleção e escolha entre os elementos da nossa cultura, exaltando uns e rebaixando outros".

A tensão entre teoria e narrativa é parcialmente acentuada quando Rorty (1990, p. 641) afirma que tanto os sistemas filosóficos quanto os romances são instrumentos e, como tais, "podem ser torneados para todo e qualquer propósito”. Dessa maneira, embora quaisquer recursos 
argumentativos estejam igualmente disponíveis para os dois lados de uma contenda, ele acredita que atualmente devemos optar pelas narrativas em detrimento das teorias. Isto, não porque uma seja inferior a outra, ou porque haja alguma posição teórica inválida ou indefensável, mas sim porque ele considera que para a realização de muitos dos propósitos humanos contemporâneos (principalmente nas comunidades democráticas liberais), as narrativas romanescas e jornalísticas (entre outras) têm propiciado ideias contextualmente mais úteis, no sentido de explicitarem diversos detalhes sórdidos e de terem sido historicamente mais eficazes para a promoção do bem-estar social, agindo como reguladoras e criticas das atividades políticas.

Na perspectiva rortyana, embora as propostas encontradas nos textos de filósofos e teóricos sociais devam ser consideradas, elas não são tão imaginativas quanto aquelas verificadas nos gêneros literários supracitados que, por esta razão, devem ser privilegiados. Se a questão prioritária não é mais desvendar a verdade e sim buscar novos meios através dos quais a liberdade possa ser gradualmente ampliada e expandida (ou mesmo suprimida; o que serviria de alerta); então, devemos nos ater principalmente ao esforço literário de invenção de novas possibilidades. Além do reconhecimento da contingência que afeta a realidade e a humanidade, esse procedimento pragmático implica a invenção de novos instrumentos, novos vocabulários, novos jogos de linguagem e novas descrições e redescrições de pessoas e do mundo.

Em outro texto, Rorty (1995, p. 67) exara que a sua opção pela narrativa e não pela teoria, deve-se ao fato de que a filosofia ocidental ainda demonstra uma "lastimável tendência para o essencialismo" quando oferecem "comparações interculturais". Assim, a fim de evitar esta infeliz tendência filosófica ele prefere teorizar cada vez menos a respeito dos ideais que defende para, em contrapartida, apontar para casos particulares personagens, situações, temas e acontecimentos - expressos em romances que ilustrem exemplarmente a forma que as coisas assumem quando tais ideais são colocadas em prática ou, ao contrário, quando são negligenciados. Essa alternativa é, conforme seu relato, baseada na sugestão 
kunderiana de que o romance é, predominantemente, o gênero literário que possui maior identidade com os valores democráticos e com a luta em prol da liberdade e igualdade.

Desse modo, Rorty (1995) alega que a importância relativa da teoria e da narrativa para as sociedades pode ser pensada nos seguintes termos: no Ocidente, a consciência e a sensibilidade dos indivíduos diante dos dramas e tragédias de outras pessoas são reputadas mais aos esforços de romancistas como Orwell e Dickens do que de filósofos como Platão e Marx. Aqui, a explicação rortyana se resume a constatação de que os romancistas, mais do que os filósofos ou os poetas, são bons em oferecer detalhes. Entretanto, posteriormente, Rorty (1998) observa que é justamente a exposição - às vezes inédita - de detalhes que capacitam as grandes obras literárias a inspirar, em épocas distintas, inúmeras pessoas que terminam por recontextualizarem e reformularem as suas crenças.

Kundera (1994), ao comentar a capacidade que as narrativas literárias têm de mudar a concepção e costumes das pessoas, destaca que sua própria visão acerca do sagrado e do profano foi intermediada pela exploração que Thomas Mann faz dos textos sagrados. Não obstante, o relato da reformulação de suas crenças, oferece um bom exemplo do tipo de efeito acarretado pelas narrativas para minar intolerâncias:

fui educado como ateu e isso me agradou até o dia em que, nos anos mais negros do comunismo, vi cristãos perseguidos. Na mesma hora, o ateísmo provocador de minha primeira juventude desapareceu como uma bobagem juvenil. Compreendia que meus amigos religiosos e, movido pela solidariedade e pela emoção, acompanhava-os às vezes à missa. Ao fazer isso, não sentia a convicção de que existe um Deus como um ser que dirige nossos destinos. Em todo caso, o que poderia eu saber? E eles, o que poderiam saber? Estariam certos de estar certos? Ficava sentado na igreja com a estranha e feliz sensação de que a minha não-crença e a crença deles estavam curiosamente próximas (KUNDERA, 1994, p. 10).

Nessa perspectiva, Rorty (1994, p. 19) acredita que podemos contribuir para a efetivação da solidariedade humana por intermédio 
da ampliação de nossa imaginação. Segundo ele, isto ocorreria mediante o ato de contar histórias: narrativas dramáticas ou inspiradoras sobre comunidades, instituições e indivíduos que, grosso modo, contribuiriam para que as próximas gerações dessem continuidade (e amplitude) aos inacabados projetos pluralistas e igualitários das sociedades democráticas; auxiliariam no aumento da tolerância das pessoas para com a diversidade étnica e cultural; e, finalmente, motivariam ações tais como a invenção de novos vocabulários - através dos quais novos direitos poderiam ser formulados. Estas histórias seriam apresentadas em romances, contos, etnografias, produções cinematográficas, artigos jornalísticos, documentários televisivos, histórias em quadrinhos, músicas, poesias, peças teatrais, Internet e afins.

A relevância das narrativas nesse processo educativo pode ser verificada quando Rorty (1998) sustenta que a leitura de livros como o Novo Testamento e o Manifesto comunista deveria ser encorajada tanto por pais quanto por professores, pois o conhecimento de tais narrativas (e a posterior reação a ela) contribuiria para que as próximas gerações fossem moralmente melhores. Em geral, esta seria a esperança rortyana de que os jovens das próximas gerações, ao elaborarem suas próprias narrativas (sob a forma de romances, filmes, leis, instituições etc.) se lembrem de ampliar o raio de ação do termo nós, por mais estranho ou louco que tal descrição - ou redescrição - possa parecer para muitos de seus contemporâneos. Ele escreve:

os nossos filhos têm de aprender, desde cedo, a enxergar as desigualdades de suas fortunas e aquelas de outras crianças não como a 'Vontade de Deus', nem como 'o preço necessário da eficiência econômica', mas como uma tragédia evitável. Eles devem começar a pensar, o mais cedo possível, sobre como modificar o mundo, de modo a fazer com que ninguém passe fome enquanto outros se empanturram.

As crianças precisam ler a mensagem de fraternidade humana de Cristo em conjunto com o relato de Marx e Engels sobre como o capitalismo industrial e o mercado livre - indispensáveis como são hoje - tornaram muito difícil instituir essa fraternidade. Elas precisam ver suas 
vidas como esforços no sentido de realizar a nossa potencialidade moral, inerente a nossa capacidade de comunicar as nossas necessidades e esperanças. Elas devem ouvir histórias sobre as congregações cristãs que se reuniam nas catacumbas e sobre os comícios operários nas praças de metrópoles. De fato, ambos cumpriram papéis igualmente importantes no longo processo de realização dessas potencialidades (RORTY, 1998, p. 7).

Em outras palavras, Rorty (1994, p. 222) espera que possamos transformar partes do mundo, redescrevendo-o. Essa ideia prescinde do pressuposto universalista que sustenta a existência de uma essência humana comum em todos os seres humanos e, em contrapartida, investe em dois atributos comuns à humanidade: a humilhação, compreendida como a ideia de que todos são passíveis de sofrer um "tipo especial de dor", que "todos podem ser humilhados pelo desmantelamento forçado das estruturas particulares de linguagem e de crença nas quais foram socializados (ou que se orgulham de ter formado por si próprios)"; e a narrativa, a capacidade de contar histórias sobre sofrimentos ou triunfos passados e também sobre cenários alternativos, preferíveis aos atuais.

$\mathrm{Na}$ acepção rortyana, a fim de compreender ou justificar uma ação genocida, tanto as vítimas quanto os algozes podem até tentar inutilmente negar a humanidade uns dos outros; mas ninguém pode negar que se algo de ruim acontece com uma pessoa 'estranha' do outro lado do mundo o mesmo pode acontecer com qualquer um de nós. Assim, devemos nos importar com pessoas desconhecidas e contar a sua dramática história. E, para convencer outras pessoas a ajudar indivíduos diferentes (no que tange ao país, raça, costumes, religião, etc.) podemos concluir nosso relato com algo do tipo: 'devemos nos importar com ela porque isso poderia ter acontecido com um amigo seu'; ou ainda 'ela poderia ser sua filha'. Nesse sentido, a solidariedade que apela para o individualismo das pessoas faz mais pela comunidade do que qualquer tentativa de justificação universalista.

Nesse sentido, convém lembrar que para Rorty, a solidariedade humana não deve ser concebida como um fato a ser descoberto, mas sim 
como um objetivo a atingir. A realização desse projeto passaria, necessariamente, pela ação da imaginação: isto porque as dores e humilhações afetam todos os seres humanos e a nossa capacidade imaginativa permite que ampliemos a nossa sensibilidade ao sofrimento alheio. Assim, através desta experiência redescritiva é possível criar a solidariedade onde antes havia apenas a indiferença gerada por uma rígida distinção ente o nós e o eles.

\section{Considerações finais}

O caso paradigmático de romancista que oferece detalhes ou pequenas advertências é George Orwell (1903-1950). Sua obra 1984, um romance político publicado originalmente em 1949, encerra sobretudo uma crítica contumaz ao totalitarismo. Seja na sua vertente destra, com o fascismo e o nazismo, seja na sua vertente sinestra, com o comunismo. O perturbador universo totalitário orwelliano é uma distopia na qual vive Wiston Smith. O Estado opressivo e dominador transforma a fração majoritária da população em farrapos humanos que seguem cegamente líderes anônimos, cujo poder é exercido através de mecanismos de controle, condicionamento de conduta e programas supressores de ideias autônomas. Além da miséria física, gradativamente, o cidadão, representado por Wiston Smith, é destituído de suas - até então remanescentes - crenças, esperança e liberdade.

A ficção orwelliana se confunde com a realidade já vivenciada por muitos países. E o temor maior é que muitos dos componentes da trama podem, infelizmente, ser realizados de forma enviesada, pelos líderes de muitas nações, num futuro próximo. Eis exemplos das técnicas e outros recursos empregados em prol da dominação: o programa (e o condicionamento resultante) dos Dois Minutos de Ódio; a Polícia do Pensamento e os ideocriminosos; os Livros e notícias jornalísticas reescritos; o onipotente Partido; o onisciente Grande Irmão; a onipresente Novilíngua; a Tortura; o Ministério da Verdade com o seu lema-lei triplo: 
“Guerra é paz, liberdade é escravidão, ignorância é força”. E, finalmente, o Duplipensar. Como define Orwell (1996, p. 200): "Duplipensar quer dizer a capacidade de guardar simultaneamente na cabeça duas crenças contraditórias, e aceitá-las ambas".

Assim, parafraseando Kundera, podemos dizer que a hipótese ontológica de Orwell reside na ideia que o principal ataque à humanidade principia com a redução de seu vocabulário: diminui-se a linguagem e, por conseguinte, restringe-se a consecução das potencialidades humanas. Tal advertência talvez pudesse ser aquiescida por Rorty e Benjamin. Vejamos.

Rorty (1994) considerava que as culturas são vocabulários corporificados. Nesse sentido, ele concebe a educação como uma combinação entre dois processos contínuos e complementares: a socialização e a individualização (RORTY, 2000). No primeiro caso, as pessoas recebem valores (normas de comportamento, regras e leis) que as ajudarão no relacionamento cotidiano com as pessoas de seu grupo social; no segundo caso, as pessoas tomam conhecimento de perspectivas alternativas que criticam os valores assimilados e, em alguns casos, apresentam valores novos. Esse processo de crítica e posterior redescrição dos indivíduos pode ser iniciado tanto por intermédio dos ensinamentos de um professor quanto por narrativas, que podem inspirar a ampliar o respeito e o diálogo com outras culturas ou vocabulários, ou ainda podem prevenir sobre possíveis perigos que a humanidade corre ao promover práticas totalitárias.

Benjamin (1986) desconfiava dos documentos oficiais e propunha a releitura a contrapelo dos bens culturais. Para ele, a história é sempre contada pelos vencedores ou pela classe dominante. Nessa linha de pensamento, o educador deve ser um historiador crítico: alguém que, na acepção benjaminiana, deve escovar a história a contrapelo, isto é, na direção contrária das tendências em voga. Assim, propõe-se que ao invés de apenas reproduzir relatos, o educador investigue e participe da vida daqueles que vivem às margens da sociedade. Esse é o sentido de educar a contrapelo: significa educar contra a barbárie. E a tarefa do educador é descobrir o que está por baixo: ver as narrativas que não foram contadas, trazer para dentro da escola o que a versão dos vencedores não contou. 
Isso talvez contribuísse para permitir a formação de uma mentalidade crítica nos jovens, além de dar a eles voz para contarem a história da sua comunidade. Nesse contexto, a juventude que não faz parte da elite dominante não é rotulada e estigmatizada, mas é convidada a dar a sua versão dos fatos e, assim, se tornarem narradores de suas próprias histórias.

\section{Referências}

BENJAMIN, W. O narrador. In: Textos escolhidos. Tradução de Erwin Theodor Rosental. São Paulo: Abril Cultural, 1975. p. 63-81.

BENJAMIN, W. Documentos de cultura, documentos de barbárie. São Paulo: Cultrix; EDUSP, 1986.

KUNDERA, M. A arte do romance. Tradução de Teresa Bulhões C. da Fonseca e Vera Mourão. Rio de Janeiro: Nova Fronteira, 1988.

KUNDERA, M. Os testamentos traídos. Tradução de Teresa Bulhões C. da Fonseca e Maria Luiza Newlands Silveira. Rio de Janeiro: Nova Fronteira, 1994.

ORWELL, G. 1984. 23. ed. Tradução de Wilson Velloso. São Paulo: Nacional, 1996.

RORTY, R. Truth and Freedom: a reply to Thomas McCarthy. Critical Inquiry, v. 16, p. 633-643, 1990.

RORTY, R. Contingência, ironia e solidariedade. Tradução de Nuno Ferreira da Fonseca. Lisboa: Presença, 1994.

RORTY, R. Heidegger, Kundera, and Dickens. In: RORTY, R. Essays on Heidegger and others: philosophical papers. Cambridge, UK: Cambridge University Press, 1995. v. 2, p. 66-82.

RORTY, R. The inspirational value of great works of literature. In: RORTY, R. Achieving our country. Cambridge: Harvard University Press, 1997. p. 125-140. 
RORTY, R. Duas profecias. Folha de S. Paulo, São Paulo, 24 maio 1998. Caderno Mais!, p. 7.

RORTY, R. Educação como socialização e como individualização. In: GHIRALDELLI Jr., P. Filosofia da educação. Rio de Janeiro: DP\&A, 2000. p. 81-97.

Recebido: 31/08/2010

Received: 08/31/2010

Aprovado: 10/10/2010

Approved: 10/10/2010 